\title{
SISTEMAS GEOMORFOLÓGICOS MONTANHOSOS E SUA REPRESENTAÇ̃̃O CARTOGRÁFICA: MAPEAMENTO DOS FATOS GEOMÓRFICOS NO HORST DO CAPARAÓ (MG/ES)
}

\author{
Roberto Marques Neto $^{(\mathrm{a})}$, Juliana Alves Moreira ${ }^{(\mathrm{b})}$, Felipe Pacheco da Silva ${ }^{(\mathrm{c})}$ \\ (a) Departamento de Geociências, Programa de Pós-graduação em Geografia/ Universidade Federal de Juiz de \\ Fora, roberto.marques@ufjf.edu.br \\ (b) Departamento de Geociências/Universidade Federal de Juiz de Fora \\ ${ }^{(c)}$ Departamento de Geociências/Universidade Federal de Juiz de Fora
}

\section{Eixo: SISTEMAS GEOMORFOLÓGICOS: ESTRUTURA, DINÂMICAS E PROCESSOS}

\begin{abstract}
Resumo
A representação cartográfica dos sistemas geomorfológicos não tem sido pauta plenamente consensual, sendo permeada por um rol de desafios metodológicos que avultam na inserção do complexo plano de informações que um mapa geomorfológico deve conter. No que tange especificamente às paisagens montanhosas, como horsts contínuos e grandes estruturas antiformais, a representação dos fatos geomórficos interpretados demanda estratégias que atendam às especificidades de sistemas geomorfológicos desta estirpe. O presente paper discute a problemática da cartografia do relevo em domínios montanhosos a partir da interpretação e mapeamento do horst do Caparaó, vultuosa lasca tectônica que marca a divisa entre os estados do Espírito Santo e Minas Gerais, tendo sido discernida uma compartimentação geomorfológica estabelecida por diferentes patamares altimétricos delimitados por knicks gerados por significativo controle morfotectônico, deflagrador de fatos geomórficos representados por símbolos e que indicam significativas alterações nas formas e processos sob uma forte influência de tectônica ativa e ressurgente.
\end{abstract}

Palavras chave: horst do Caparaó; controle tectônico; cartografia geomorfológica.

\section{Introdução}

Ao longo do Brasil Oriental ocorrem interessantes regiões geomorfológicas caracterizadas por topografia montanhosa, com destaque para as áreas sob a influência mais direta do rifte continental do sudeste do Brasil (sensu RICCOMINI, 1989), ao qual se vinculam sistemas geomorfológicos nos quais dominam os modelados de dissecação em controle estrutural, como a Serra do Mar, a Serra da Mantiqueira e o domínio dos alinhamentos de cristas do Vale do Rio Paraíba do Sul. São relevos de gênese tectônica, morfometricamente caracterizados por declives acentuados e dissecação profunda e que se encontram, em grande medida, afetados por tectônica ressurgente e ativa.

No plano da representação cartográfica do relevo, a diferenciação entre os modelados de dissecação em controle estrutural e aqueles de dissecação mais homogênea tem apoio contundente nos produtos de sensoriamento remoto, como imagens de satélite e imagens de radar tratadas em modelo sombreado, que podem ser compartimentalizados a partir do comportamento mais isotrópico ou anisotrópico das imagens. Em geral, os modelados de dissecação em controle estrutural, na forma de cristas, escarpas dissecadas em bloco falhado, morros alinhados profundamente dissecados, 
apresentam textura mais rugosa nos imageamentos aeroespaciais, ao passo que tipos genéticos mais homogeneamente dissecados em morros e colinas convexas com drenagem tipicamente em padrão dendrítico a subdendrítico assumem texturas mais lisas em sua resposta espectral.

A diferenciação acima contextualizada permite uma compartimentação prévia do relevo e tem boa aplicabilidade nas interpretações regionais. Os modelados em controle estrutural, quando visualizados a partir de unidades mais específicas em escala de detalhe a semidetalhe, como estruturas antiformais extensas e elevadas, apresentam algumas especificidades que reverberam nas estratégias de representação cartográfica. Muitas vezes, a interpretação dos fatos geomórficos ressalta forte lateralidade nos processos de superfície que operam em diferentes unidades topomorfológicas que se sucedem dos sopés até os somitais, normalmente definidas a partir dos knicks que delimitam compartimentos de topos, taludes, escarpas, patamares reafeiçoados, etc. Proposições como a de Silva (2000) e Cunha e Mendes (2005) atendem ao mapeamento de sistemas geomorfológicos com tais especificidades, conforme foi aplicado por Marques Neto et al. (2016) no horst do Caparaó, imponente pilar tectônico localizado na Mantiqueira Setentrional (sensu GATTO et al. 1983) na divisa entre os estados de Minas Gerais e Espírito Santo. A partir de tal proposta de compartimentação, o presente paper visa avançar na discussão sobre o sistema geomorfológico definido pelo maciço do Caparaó tomando como suporte a cartografia geomorfológica como ferramenta para interpretação dos fatos geomórficos vigentes.

\section{Materiais e métodos}

Os processos de compartimentação geomorfológica em escala de semidetalhe a partir dos padrões de formas semelhantes (ROSS, 1992) tem demonstrado ampla aplicabilidade na distinção de diferentes tipos genéticos e na interpretação destes em suas relações com os contextos estruturais de origem. Colinas sedimentares e morros emoldurados em rochas cristalinas são morfologias denudacionais de fácil distinção na paisagem, e sua representação cartográfica tende a ser resoluta. Aprofundando o detalhamento em um compartimento ou outro, as colinas podem ser dissociadas segundo as dimensões interfluviais em amplas, médias ou pequenas (PONÇANO et al. 1981), e os morros se manifestam mais ou menos alongados, convexos ou aplainados em seus topos e vertentes, sendo assim passíveis de diferenciação de acordo com os aspectos morfológicos e morfométricos correlatos aos processos evolutivos aos quais tais formas estiveram submetidas ao longo do Cenozoico, fundamentalmente durante o Quaternário.

Quando o mapeamento se dá em um único tipo genético de dimensões consideráveis, as estratégias metodológicas devem dar conta de discernir os diferentes aspectos evolutivos que engendraram diferentes compartimentos e fatos geomórficos em uma mesma morfoestrutura, termo este aqui tratado apenas com base na relação direta entre uma expressão geomorfológica e um contexto litoestrutural específico, e não propriamente fechado na acepção taxonômica postulada por autores como Gerasimov 
OS DESAFIOS DA GEOGRAFIA FÍSICA NA FRONTEIRA DO CONHECIMENTO

Instituto de Geociências - Unicamp

Campinas - SP

28 de Junho à 02 de Julho de 2017

(1968) e Ross (1992). É o caso do horst do Caparaó, estrutura anticlinal balizada em gnaisses e granitos que se projeta em pronunciado desnivelamento entre os modelados de dissecação homogênea em morros e morrotes que predominam no contexto regional.

Diante de tal realidade, a compartimentação geomorfológica da referida estrutura se pautou no discernimento de diferentes unidades topomorfológicas, em princípios semelhantes aos trabalhados por Cunha e Mendes (2005). O maciço do Caparaó foi delimitado na escala de 1/50.000 a partir das respectivas folhas topográficas do Instituto Brasileiro de Geografia e Estatística (Divino de São Lourenço - SF-24-V-A-IV-2, Iúna - SF-24-V-A-I-4, Espera Feliz - SF-24-V-A-IV-1, Manhumirim SF-24-V-A-I-3) e com o auxílio de imagens de radar SRTM (Shuttle Radar Topography Mission) em relevo sombreado imageado em quatro ângulos azimutais de iluminação $\left(45^{\circ}, 90^{\circ}, 315^{\circ}\right.$ e $\left.360^{\circ}\right)$. Sobre as folhas foram delimitados diferentes patamares, da base das vertentes escarpadas do horst em demanda aos somitais.

A rede de drenagem foi extraída a partir das folhas topográficas supracitadas com o uso do ArcGIS, ambiente no qual a malha hidrográfica foi sobreposta ao relevo sombreado. Doravante, a partir da interpretação integrada do relevo sombreado com as bases planialtimétricas foi estabelecida uma coleção de fatos geomórficos de caráter morfoestrutural e morfotectônico para os quais foram estabelecidas simbologias de representação, aprimorando o documento cartográfico mediante a represtação do relevo simbolizado, consolidada em proposições metodológicas como as de Tricart (1965), Nunes et al. (1994), Gustavsson et al. (2006) e Cunha (2012). Subsequentemente, através do ArcGIS, a compartimentação geomorfológica foi sobreposta ao mapa de relevos simbolizados, gerando-se um mapa síntese depositário de informações morfológicas, morfométricas, morfoestruturais e morfotectônicas. Os litotipos não foram incorporados ao mapa, pois o uso de hachuras na sua representação comprometeria a higiene cartográfica em uma representação cujo plano de informações já é adensado. Em compensação, a base geológica é apresentada em um documento cartográfico a parte que permite plenamente a abstração entre os compartimentos de relevo e demais fatos geomórficos e os litotipos encontrados no maciço.

Os aspectos morfodinâmicos foram estabelecidos a partir do trato morfométrico, pautado na quantificação da dimensão interfluvial e da profundidade de dissecação. Estruturas anticlinais na forma de cristas alongadas e domos normalmente apresentam padrão de drenagem radial nos somitais que tendem a paralelização no domínio das vertentes, tendo sido estabelecida a incisão vertical para os diferentes níveis no intuito de saber o comportamento erosivo da drenagem nos diferentes patamares escalonados. Para os topos e altas encostas foi mensurada apenas a dimensão interfluvial, uma vez que tais compartimentos encontram-se preservados da vaga erosiva remontante da drenagem que disseca as escarpas e degraus escalonados do horst. Os valores foram organizados em uma matriz de dissecação, rotina metodológica muito corrente na cartografia geomorfológica brasileira (vide GATTO et al., 1983; ROSS, 1992; NUNES et al. 1994; CUNHA, 2012; MARQUES NETO et al. 2015). Em 
complemento, informações acerca das coberturas superficiais, também de nexo morfodinâmico, foram elucidadas no corpo da legenda a partir da descrição de cada compartimento. Ainda, o corpo da legenda também traz informações geocronológicas relativas.

O produto cartográfico final segue apresentado na escala de 1/50.000, compatível com a expressão sub-regional do horst do Caparaó, e, tal como os mapas intermediários, foi editado em ArcGIS. Sincronicamente, as campanhas de campo subsidiaram a interpretação das formas e processos, buscando, sempre que exequível, validar in locu os relevos simbolizados interpretados por sensoriamento remoto.

\section{O horst do Caparaó enquanto indivíduo geográfico}

Um indivíduo geográfico pode ser entendido como uma integridade heterogênea designada por Sochava (1978) como geócoro, consubstanciada a partir da conjugação de diferentes tipologias (geômeros), conceitos chave no princípio bilateral de interpretação e classificação dos geossistemas terrestres postulados pelo insigne geógrafo eslavo. Nesse sentido, o horst do Caparó se projeta como estrutura anticlinal de destaque, única e magnânima entre conjuntos de formas convexas do tipo "mar de morros" (sensu AB'SÁBER, 1965, 2003), com os quais estabelece desníveis que se aproximam de 2000 metros. Posicionado na extremidade norte da Mantiqueira Setentrional (sensu GATTO et al. 1983), marcando a divisa entre os estados de Minas Gerais e Espírito Santo, figura como pilar tectônico de destaque numa região caracterizada por um rebaixamento erosivo mais expressivo do relevo em função do controle exercido por diferentes níveis de base, direta ou indiretamente conectados ao Oceano Atlântico. A estrutura em apreço é balizada por gnaisses ortoderivados e migmatitos de composição granítica a diorítica paleoproterozoicos pertencentes à Suíte Caparaó, tendo os migmatitos sua ocorrência constatada na parte central da serra, com presença de gnaisses nas bordas, conforme documentado por Novo et al. (2011), visualizável pela figura 1.

Do Pico da Bandeira, marco geográfico de referência por sua condição de ponto culminante de todo o Brasil extra-amazônico com 2892 metros de altitude, até o contato tectônico com o rio Caparaó a aproximadamente 800 metros, o anticlinal se escalona em escarpas de falha caracterizadas por declives extremos que se suavizam nos patamares mais inferiores, tanto para leste como para oeste, mantendose um significativo entalhe vertical como padrão geral deste sistema geomorfológico.

Os aspectos morfológicos e morfométricos das vertentes, juntamente aos níveis altitudinais, estabelecem estreitas relações com a cobertura vegetal. Nos patamares mais baixos ocorrem as fitofisionomias em Floresta Estacional Semidecidual e Ombrófila Densa Alto-montana, que ocorrem até a faixa de 1800 metros, patamar a partir do qual fatores pedológicos e climáticos se impõem como limitantes ao desenvolvimento de macrofanerófitos. As associações de Latossolos e Cambissolos conspícuas nos patamares inferiores reafeiçoados e suavizados em seus declives, dadas fundamentalmente por colúvios pedogeneizados, dão passagem a um domínio de Neossolo Litólico e 
XVII Simpósio Brasileiro

de Geografia Fisica Aplicada

I Congresso Nacional

de Geografia Física

\section{OS DESAFIOS DA GEOGRAFIA FÍSICA NA FRONTEIRA DO CONHECIMENTO \\ Instituto de Geociências - Unicamp \\ Campinas - SP \\ 28 de Junho à 02 de Julho de 2017}

afloramentos extensivos. Além das mudanças nos sistemas de transformação pedológica, os efeitos do clima tropical de altitude se intensificam, com rebaixamento das temperaturas médias anuais e aumento das amplitudes térmicas diárias. Tais fatores coincidem com a passagem dos domínios florestais para os campos altimontanos (herbáceos, arbustivos ou em associações complexas) que medram sobre solos rasos e ricos em minerais primários vigentes nos patamares mais elevados.

A delimitação da estrutura do Caparaó praticamente se sobrepõe aos limites de uma unidade de conservação de proteção integral (Parque Nacional do Caparaó), o que restringe a ocupação antrópica às estruturas administrativas e de visitação do parque. Imediatamente ladeado ao perímetro da reserva, no entanto, o uso da terra é bastante intenso, e se estabelece majoritariamente pela cafeicultura e acessoriamente pela pastagem e silvicultura de Eucalyptus, o que aborta a possibilidade de uma zona de amortecimento funcional e tende a intensificar, por conseguinte, as pressões e efeitos de borda.

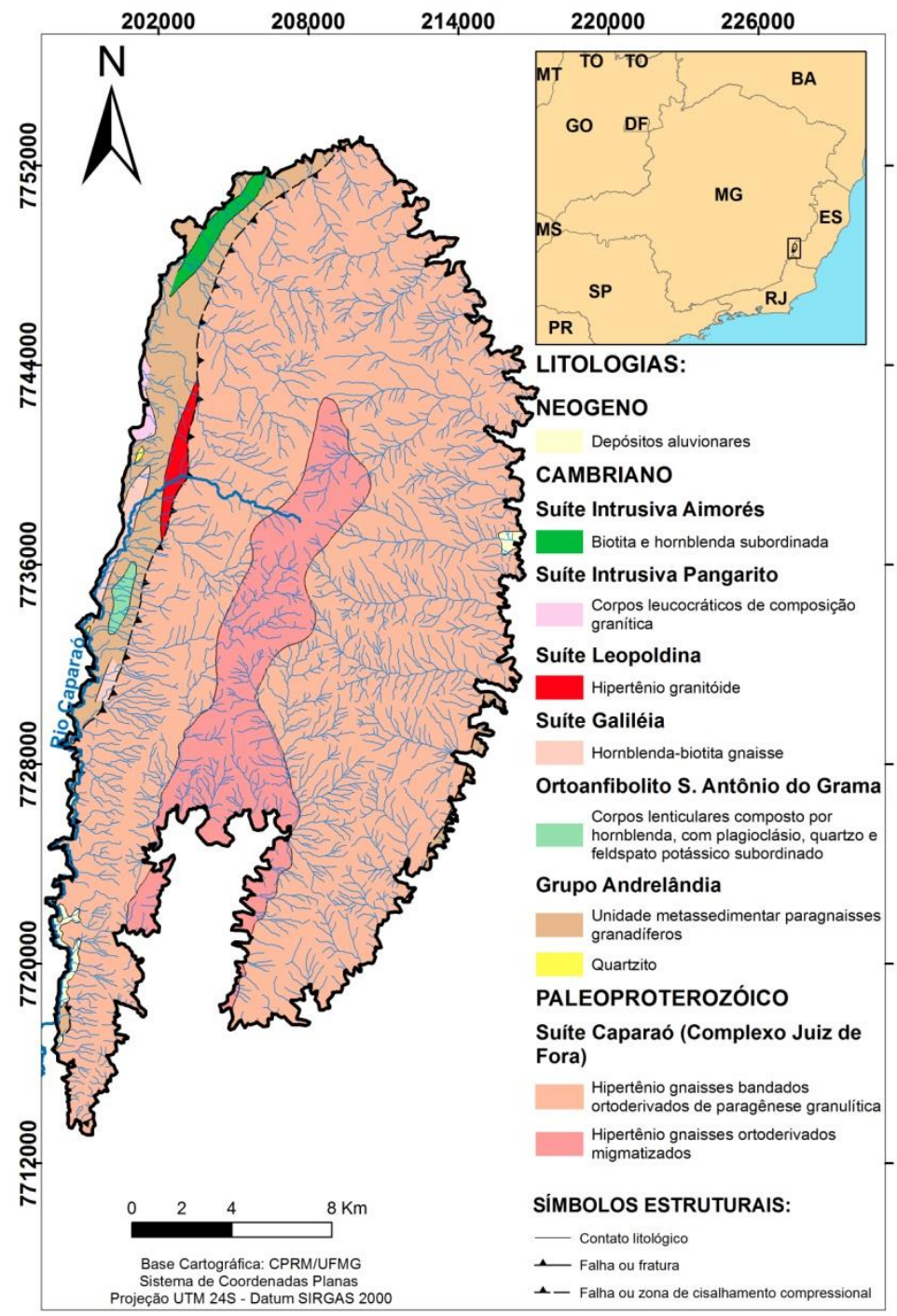

Figura 1 - Localização e base geológica do horst do Caparaó.

\section{Resultados}




\section{OS DESAFIOS DA GEOGRAFIA FÍSICA NA FRONTEIRA DO CONHECIMENTO \\ Instituto de Geociências - Unicamp \\ Campinas - SP \\ 28 de Junho à 02 de Julho de 2017}

O horst do Caparaó figura como a mais elevada estrutura entre as lascas tectônicas posicionadas na extremidade norte da Mantiqueira Setentrional, facilmente delimitável entre os modelados de dissecação homogênea que o circundam. Das superfícies de cimeira em direção aos fundos de vale adjacentes formatam-se diferentes unidades topomorfológicas (figura 2) controladas por intervenções erosivas e tectônicas cuja interpretação fornece elementos importantes acerca da evolução cenozoica do maciço.
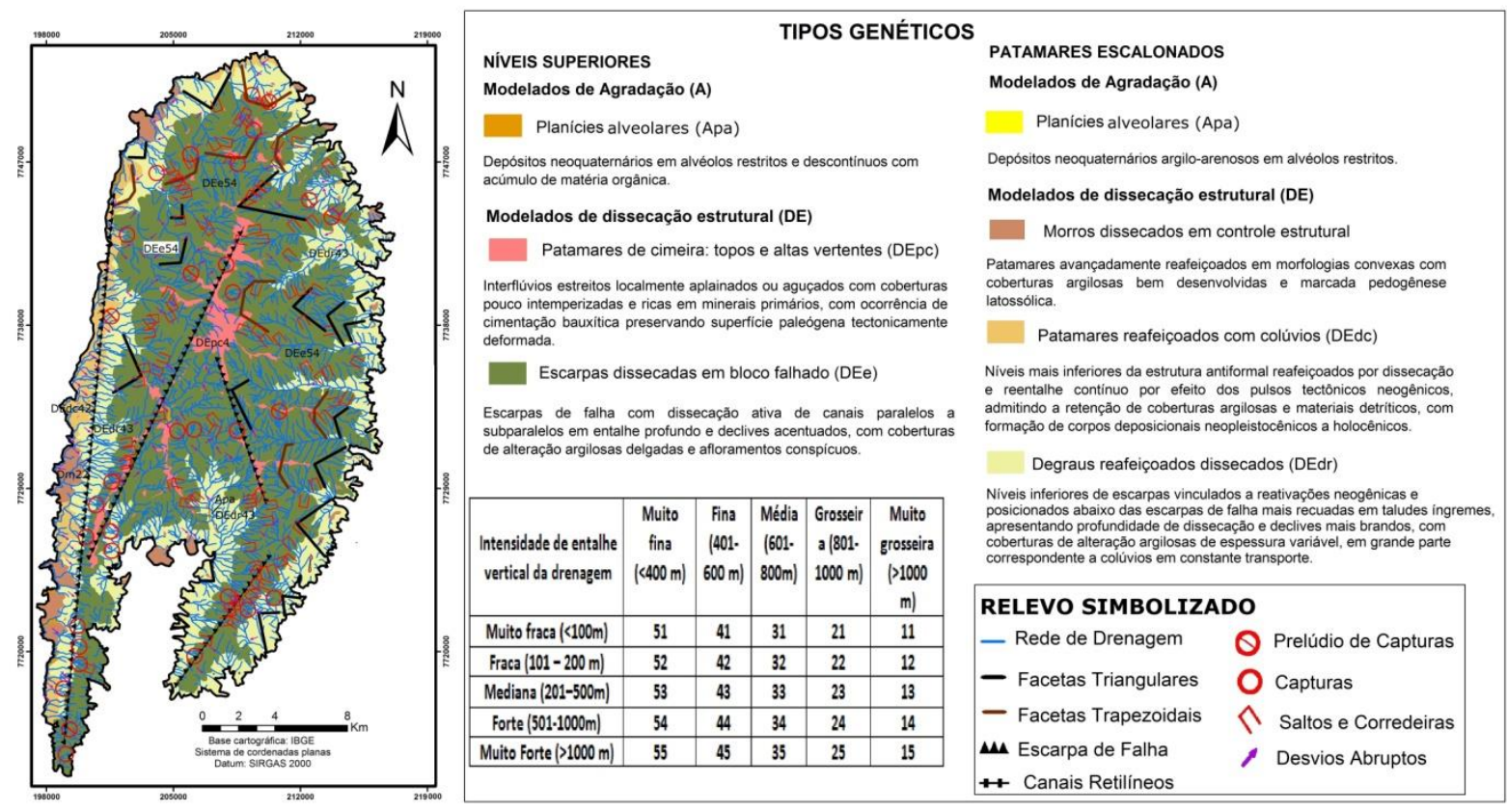

Figura 2 - Carta geomorfológica do horst do Caparaó (ES/MG)

Regionalmente, os pilares tectônicos remanescentes na Mantiqueira Setentrional, diferentemente do horst contínuo e sobrelevado que caracteriza seu ramo meridional, encontram-se descontínuos e festonados por cortes epigênicos levados a efeito por rios de considerável potência erosiva direta ou indiretamente conectados ao Oceano Atlântico, como os rios Novo e Pomba mais ao sul, e o rio Carangola mais a norte, que disseca um bloco abatido entre as serras do Caparaó e do Brigadeiro, latitudinalmente parelhas e disjuntas pelo front erosivo capitaneado pelo referido curso d'água. Os alinhamentos mais elevados, cuja orientação geral NE-SW mantém consonância ao sistema rifte continental do sudeste do Brasil (sensu RICCOMINI, 1989), constituem zonas de cisalhamento que tem respondido de forma mais veemente às solicitações tectônicas mais recentes e ativas, conforme atinado por Oliveira et al. (2014) na região da bacia do rio Pomba e por Marques Neto et al. (2016) no próprio Caparaó.

A estrutura anticlinal do Caparaó apresenta patamares de cimeira estreitos parcialmente aplainados intercalados a formas aguçadas, limitando extensas escarpas de falha transfiguradas em taludes 
contínuos ou talhadas em facetas trapezoidais a triangulares, o que denota fortemente uma evolução tectônica (STWEART e HANCOCK, 1990) dessas frentes escarpadas que ocupam a maior parte da área de estudo. Sobre elas, foram diferenciadas as escarpas contínuas e os setores caracterizados por facetamento trapezoidal ou triangular, supondo o provável avanço erosivo nas feições trianguladas e basculamentos tectônicos mais veementes nos blocos onde as escarpas encontram-se mais integralmente preservadas. A falha normal em movimentação que comanda a evolução remontante das escarpas (figura 1) delimita a oeste os compartimentos de degraus e patamares reafeiçoados, por vezes estabelecidos em níveis de base locais e mudanças de ordem da hierarquia fluvial. Tal delimitação coincide também com o contato entre as litologias paleoproterozoicas da Suíte Caparaó e rochas do Grupo Andrelândia e outros corpos granitoides, alguns deles relacionados aos morros dissecados em controle estrutural. Pelo lado leste, o controle erosivo tem se demonstrado mais efetivo pelo reafeiçoamento mais expressivo verificado na base das escarpas e maior evolução dos vales que avançam remontantemente ao maciço.

O compartimento das escarpas dissecadas em bloco falhado apresenta os aspectos morfométricos mais agudos em termos de declividade e profundidade de dissecação, com desníveis que ultrapassam 1000 metros entre os somitais do maciço e os primeiros níveis de base locais. Os interflúvios também são estreitos em função da alta densidade de drenagem em padrão paralelo a subparalelo que disseca vertentes longas e íngremes, ladeando os principais canais que se dispersam radialmente das cimeiras e que, no domínio das vertentes, se arranjam na direção E-W, pela qual entalham profundamente. Os processos morfodinâmicos vigentes no contexto das escarpas são caracterizados por intenso retrabalhamento, com movimentos de massa e quedas de blocos copiosas, o que faz por revelar um sistema geomorfológico de elevadíssima energia, marcado pela presença de vales profundos e encaixados que tendem à retilinidade, e quase ausência de morfologias agradacionais . No domínio das cristas, apenas uma planície alveolar turfosa de cimeira foi passível de mapeamento na escala trabalhada, constituindo, juntamente a outras diminutas barreiras geoquímicas disjuntas e pontuais, uma feição de exceção em um sistema geomorfológico de forte movimentação lateral no qual a acumulação não é a tendência.

A profundidade de entalhe diminui substancialmente nos degraus reafeiçoados em interflúvios e patamares reafeiçoados com colúvios, onde pequenos alvéolos de acumulação começam a se formar, além da própria planície fluvial do rio Caparaó que demarca o limite da área de estudo. As coberturas de alteração são mais espessas nos níveis topomorfológicos inferiores, em geral formadas por colúvios pedogeneizados transportados das zonas transmissoras à montante, no caso, as escarpas do Caparaó; entremeados a Latossolos e Cambissolos argilosos encontram-se blocos de variado tamanho transportados gravitacionalmente do domínio das escarpas. Embora os degraus e patamares desempenhem uma função geoecológica majoritariamente transmissora, certa retenção de material 
pode ser constatada, e que em algumas extensões tem engendrado coberturas superficiais mais evoluídas.

Embora similares em termos de seus aspectos morfométricos e da densidade de lineamentos e de drenagem (MARQUES NETO et al. 2016), as vertentes oeste e leste do horst do Caparaó apresentam evolução atual distinta. No lado oeste é que se projetam as escarpas de falha mais proeminentes, a principal delas controlando a passagem do rio Caparaó, que tende a migrar em direção à margem oposta ao maciço, o que faz sugestiva a ocorrência de um basculamento para leste. Além da migração do rio Caparaó em direção ao divisor antipodal ao maciço, outras feições morfotectônicas como níveis de terraço abandonados e mesmo afloramentos rochosos nesses terraços e em seções inferiores de vertentes, bem como o aspecto retilíneo e preservado das frentes escarpadas diante de elevada densidade de drenagem, sinalizam para um processo de soerguimento vigente. Pelo lado leste, as vertentes são mais evoluídas e retrabalhadas, com penetração remontante dos compartimentos de patamares e degraus reafeiçoados, denunciando uma dinâmica erosiva mais contundente, diferenciando-se do ímpeto tectônico mais veemente que acomete a vertente oposta pela movimentação de falhas normais de significativa projeção.

A despeito da assinalada lateralidade transfigurada em intensos processos de vertente, a evolução do relevo atende dominantemente às solicitações tectônicas que perduraram ao longo do Cenozoico, característica esta que orientou estratégias metodológicas voltadas para a inserção de símbolos representativos de fatos morfotectônicos, deveras copiosos no contexto do Caparaó. Tais feições se fazem diversificadas na área de estudo, algumas delas passíveis de representação na escala trabalhada, entre as quais foi possível considerar o forte encaixamento dos canais em elevada densidade de drenagem, a retilinidade exacerbada destes canais, as inflexões abruptas e modificações nos padrões básicos, as rupturas de declive com formação de vales suspensos, as capturas fluviais conspícuas, a presença de escarpas retilíneas e facetadas, entre outras. Em função de tais características tipificarem o sistema geomorfológico estudado, foram priorizadas na representação do relevo por símbolos, que associados à compartimentação e ao trato morfométrico, constituíram a pedra de toque do trabalho que aqui se encerra.

Em tom de finalização, a figura 3 congrega uma amostragem representativa dos fatos geomórficos interpretados e cartografados, tanto no tocante à compartimentação como no que se refere às representações simbolizadas. 


\section{OS DESAFIOS DA GEOGRAFIA FÍSICA NA FRONTEIRA DO CONHECIMENTO \\ Instituto de Geociências - Unicamp \\ Campinas - SP \\ 28 de Junho à 02 de Julho de 2017}

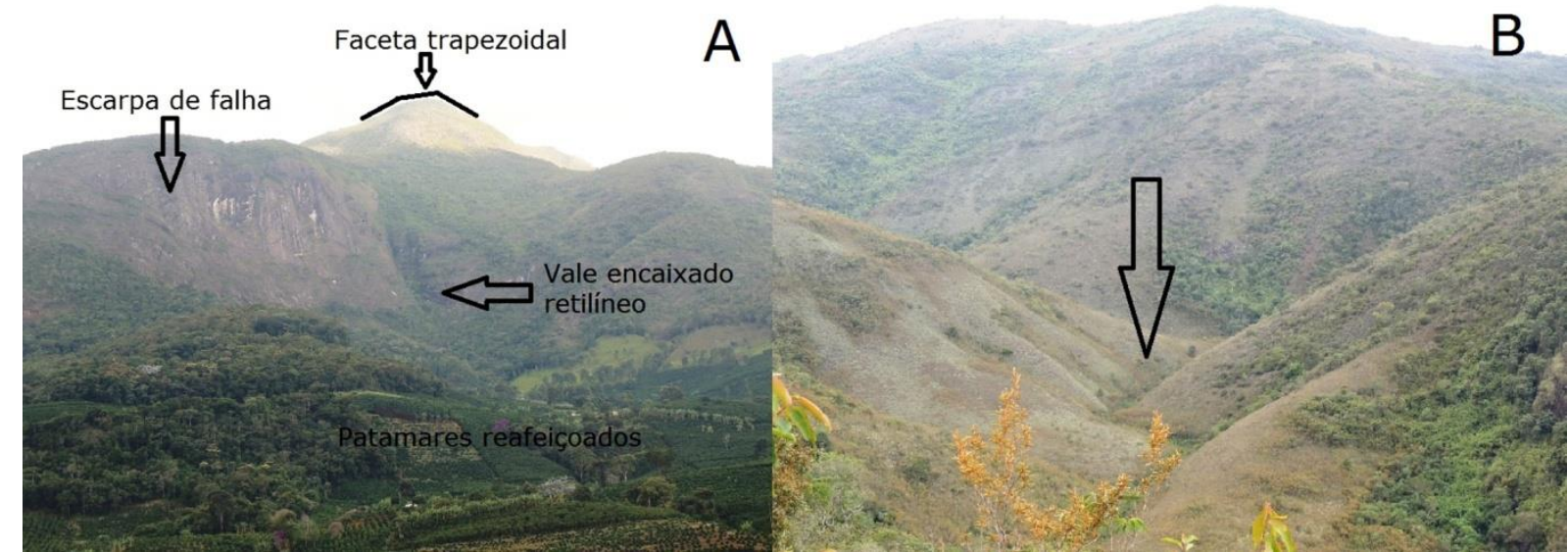

Figura 3. A) Aspectos do relevo no horst do Caparaó, destacando alguns fatos geomórficos mapeados, visualizados a partir da vertente oeste; B) Knicks abrutos e vale tectonicamente controlado com sucessivas inflexões de canais em shutter ridges bem marcadas.

\section{Conclusões}

A evolução morfológica do horst do Caparaó sobrepõe diferentes impulsos desde sua gênese vinculada ao rifte continental, partilhando das grandes zonas de cisalhamento regionais que vem apresentando soerguimento diferencial ao longo do Cenozoico, até as solicitações tectônicas recentes e ativas conjugadas aos processos de superfície catalisados pelo imperativo climático tropical. Os estreitos patamares que se formam a partir do reafeiçoamento das escarpas de falha denotam um soerguimento contínuo e consequente retrabalhamento das mesmas pela incisão fluvial. Resguardando-se de qualquer apego penckiano mais hermético, o antiforme do Caparaó encontra-se compartimentado em patamares que se escalonam dos somitais aos fundos de vale adjacentes em condição de soerguimento contínuo.

A cartografia geomorfológica apoiou de forma contundente a interpretação do sistema geomorfológico em lume, tanto em seus aspectos genéticos-evolutivos, elucidados pela compartimentação geomorfológica, como em seus aspectos morfoestruturais e morfodinâmicos, embasados pelo trato morfométrico e pela representação simbolizada do relevo. Ainda, a compartimentação segundo unidades topomorfológicas dispostas altitudinalmente permitiu uma interpretação proficiente das diferenciações existentes no interior do maciço e que são produtos de sua evolução cenozoica. Tais princípios metodológicos se fazem, portanto, bastante adequados para a compartimentação e representação cartográfica de relevos montanhosos. Os aspectos cronológicos ficam subsumidos ou restritos a aproximações relativas no corpo da legenda, uma vez que dados geocronológicos absolutos não foram gerados para a área.

A dinâmica vigente no horst do Caparaó, representada na carta geomorfológica em alguns de seus aspectos, guarda relações das mais estreitas com o sistema climático responsável pelos processos geoquímicos determinantes na geração das coberturas de alteração argilosas, bem como para as 
movimentações de superfície regidas pelo potente escoamento superficial que avulta em relevo de alta energia. Tais processos se interpenetram a um arranjo estrutural acometido por efeitos morfotectônicos, e que respondem de forma mais contundente pelo atual quadro morfológico e morfométrico sobre os quais se desenvolve uma intensa dinâmica superficial. Dessa forma, considerase que os elementos tectono-estruturais, tanto aqueles referentes aos aspectos estruturais herdados da tectônica antiga que engendrou o horst como os concernentes aos efeitos deformacionais propriamente morfotectônicos, são dominantes na evolução do sistema geomorfológico estudado, definindo sua compartimentação e influenciando fortemente os processos superficiais que ocorrem na interface com o sistema morfoclimático atual.

\section{Bibliografia}

AB'SÁBER, A. N. Domínio dos “mares de morros" no Brasil. Geomorfologia, São Paulo, n. 2, 1965.

CUNHA, C. M. L. A cartografia geomorfológica em áreas litorâneas. Tese (Livre Docência em Geografia): Rio Claro: Universidade Estadual Paulista, 2012.

CUNHA, C. M. L.; MENDES, I. A. Proposta de análise integrada dos elementos físicos da paisagem: uma abordagem geomorfológica. Estudos geográficos, v. 3, n. 1, p. 111-120, 2005.

GATTO, L. C. S.; RAMOS, V. L. S.; NUNES, B. T. A.; MAMEDE, L.; GÓES, M. H. B.; MAURO, C. A.; ALVARENGA, S. M.; FRANCO, E. M. S.; QUIRICO, A. F.; NEVES, L. B. Geomorfologia. In: Projeto RADAMBRASIL. Folha SF-23/24 Rio de Janeiro/Vitória. Rio de Janeiro: IBGE, 1983.

GERASIMOV, J. Problemas metodológicos de la ecologizacion de la ciência contemporânea. La sociedad y el medio natural. Moscou: Progresso, 1968.

GUSTAVSSON, M.; KOLSTRUP, E.; SEIJMONSBERGEN, A. C. A new symbol-and-GIS based detailed geomorphological mapping system: renewal of a scientific discipline for understanding landscape development. Geomorphology, n. 77, p. 90-111, 2006.

MARQUES NETO, R. MOREIRA, J. A.; ANDRADE, A. P.; MOURA, T. C. Horst do Caparaó: influências morfoestruturais e morfotectônicas na dinâmica e evolução do relevo. Geographia Meridionalis.

MARQUES NETO, R.; OLIVEIRA, G. C.; DIAS, J. S. Geossistemas em ambientes montanhosos: a revelação da paisagem na Serra do Caparaó (MG/ES)

MARQUES NETO, R.; ZAIDAN, R. T.; MENON JR, W. Mapeamento geomorfológico do município de Lima Duarte (MG). Revista Brasileira de Geomorfologia, v. 16, n.1, p. 123-136, 2015.

NOVO, T. A.; NOCE, C. M.; PEDROSA-SOARES, A. C.; BATISTA, G. A. P. Rochas granulíticas da Suíte Caparaó na região do Pico da Bandeira: embasamento oriental do orógeno Araçuaí. Geonomos, Belo Horizonte, v. 19, n. 2, p. 70-77, 2011.

NUNES, B. A.; RIBEIRO, M. I. C.; ALMEIDA, V. J.; NATALI FILHO, T. Manual técnico de geomorfologia. Rio de Janeiro: IBGE, 1994. 113p. (Série Manuais Técnicos em Geociências, n. 5).

OLIVEIRA, L. A. F.; MAGALHÃES JR. A, P.; LIMA, L. B. S.; CARVALHO, A. Fatores condicionantes da configuração dos fundos de vale colmatados na bacia do alto-médio rio Pomba, leste de Minas Gerais. Revista Brasileira de Geomorfologia, v. 15, n. 4, p. 639-657, 2014.

RICCOMINI, C. O rift continental do sudeste do Brasil. 1989, São Paulo, 1989. 256p. Tese de Doutorado, Instituto de Geociências, Universidade de São Paulo, São Paulo.

ROSS, J. L. S. O registro cartográfico dos fatos geomórficos e a questão da taxonomia do relevo. Revista do Departamento de Geografia. FFLCH-USP. n. 6. São Paulo, 1992. P. 17-29.

SILVA, T. M. A estruturação geomorfológica do Planalto Atlântico no estado do Rio de Janeiro. Rio de Janeiro, 2002. Tese (Doutorado em Geografia), Universidade Federal do Rio de Janeiro. 
SOCHAVA, V. B. Por uma Teoria de Classificação dos Geossistemas da Vida Terrestre. Biogeografia. São Paulo. n. 14, p. 1-24, 1978.

STEWART, I. S.; HANCOCK, P. L. What is a fault scarp? Episodes, v. 3, n. 4, p. 256-263, 1990.

TRICART, J. Principés et méthods de la géomorphologie. Mason: Paris, 1965. 496p. 